\title{
Permissivity to HCMV infection in early and term human placentae with a new ex vivo model of histocultures Charlotte Casper*1,2, Hélène Lopez ${ }^{1}$, Talal Al Saati1 ${ }^{1}$, Isabelle Dugas-Neulat ${ }^{3}$, Alain Berrebi ${ }^{4}$, Jean-Luc Davignon ${ }^{1}$ and Christian Davrinche ${ }^{1}$
}

\author{
Address: ${ }^{1}$ Inserm U563, CPTP, CHU Purpan, 31000 Toulouse, France, ${ }^{2}$ Neonatology unit, Children's Hospital, 31000 Toulouse, France, \\ ${ }^{3}$ Department of Anatomopathology, CHU Purpan, 31000 Toulouse, France and ${ }^{4}$ Department of Obstetrics, Paule de Viguier Hospital, 31000 \\ Toulouse, France \\ * Corresponding author
}

from Fourth Dominique Dormont International Conference. Host-Pathogen Interactions in Chronic Infections Paris, France. 13-15 December 2007

Published: 9 April 2008

Retrovirology 2008, 5(SuppI I):P8 doi:10.II86/I742-4690-5-SI-P8

This abstract is available from: http://www.retrovirology.com/content/5/SI/P8

(c) 2008 Casper et al.; licensee BioMed Central Ltd.

\section{Objective}

To evaluate a new ex vivo model of long term placental histocultures in order to investigate the permissivity of early and term placenta to HCMV.

\section{Material}

First trimester placentae were obtained following elective abortion and term placentae were obtained after elective caesarean section.

\section{Method}

Two methods of culture were established. Fresh placental chorionic villi were isolated, washed and distributed on collagen sponge gels as previously described [1]. Endotheliotropic HCMV strain VHL/E was left in contact with the microexplants overnight (Method A). The culture medium was collected and fresh medium added on days $1,5,10,15,21$. In method B, villi blocks were distributed on sponge gels in plates covered with subconfluent VHL/ $\mathrm{E}$ infected layers of MRC5. After 5 days, the sponge gels were transferred to plates with fresh uninfected medium only. The culture medium was collected and fresh medium added on day 6, 10, 15 and 21. Viral plaque assay in MRC5 cells was performed on each collection day. Tissue was fixed and embedded in paraffin for histopathological and immunohistochemical study with detection of immediate early antigen (IEA).

\section{Results and conclusion}

Viral infection could be seen in tissue sections of infected villi blocks after day 10 for method A in early placentae but remained negative in term placentae. Viral plaque assay showed a productive and increasing replication in supernatants at days 15 and 21 for early placentae (mean $6200 \mathrm{PFU} / \mathrm{mL}$ ) but remained negative for term placentae. Method B was efficient both for infection of early and term placentae. This is the first long term ex vivo placental model of histocultures with effective HCMV production. Our findings suggest that early placentae are more permissive to HCMV infection than term placentae.

\section{References}

I. Faye A, Pornprasert S, Dolcini G, Ave P, Taïeb J, Taupin J-L, Derrien $M$, Barré-Sinoussi F, Chaouat G, Menu E: Evaluation of the placental environment with a new in vitro model of histocultures of early and term placentae: determination of cytokine and chemokine expression profiles. Placenta 2005, 26:262-267. 